\title{
A Numerical and Experimental Study of a Novel Heat Sink Design for Natural Convection Cooling of LED Grow Lights
}

\author{
Ram Adhikari ${ }^{1}$, Dawood Beyragh ${ }^{2}$, Majid Pahlevani ${ }^{3}$ and David Wood ${ }^{1, *}$ \\ 1 Department of Mechanical and Manufacturing Engineering, University of Calgary, Calgary, AB T2N 1N4, \\ Canada; rcadhikar@ucalgary.ca \\ 2 Department of Electrical and Computer Engineering, University of Calgary, Calgary, AB T2N 1N4, Canada; \\ dawood.shekaribeyrag@ucalgary.ca \\ 3 Department of Electrical and Computer Engineering, Queen's University, Kingston, ON K7L 3N6, Canada; \\ majid.pahlevani@queensu.ca \\ * Correspondence: dhwood@ucalgary.ca; Tel.: +1-403-220-3637
}

Received: 7 July 2020; Accepted: 31 July 2020; Published: 5 August 2020

\begin{abstract}
Light-emitting diode (LED) grow lights are increasingly used in large-scale indoor farming to provide controlled light intensity and spectrum to maximize photosynthesis at various growth stages of plants. As well as converting electricity into light, the LED chips generate heat, so the boards must be properly cooled to maintain the high efficiency and reliability of the LED chips. Currently, LED grow lights are cooled by forced convection air cooling, the fans of which are often the points of failure and also consumers of a significant amount of power. Natural convection cooling is promising as it does not require any moving parts, but one major design challenge is to improve its relatively low heat transfer rate. This paper presents a novel heat sink design for natural convection cooling of LED grow lights. The new design consists of a large rectangular fin array with openings in the base transverse to the fins to increase air flow, and hence the heat transfer. Numerical simulations and experimental testing of a prototype LED grow light with the new heat sink showed that openings achieved their intended purpose. It was found that the new heat sink can transfer the necessary heat flux within the safe operating temperature range of LED chips, which is adequate for cooling LED grow lights.
\end{abstract}

Keywords: LED grow light; heat transfer; natural convection cooling; rectangular fins with openings

\section{Introduction}

For photosynthesis, plants need light of varying intensity and spectral distribution depending on their growth stages. In recent years, the use of light-emitting diode (LED) grow lights in large-scale indoor farming is increasing exponentially due to their ability to stimulate plant growth by providing controlled amounts of light at various growth stages [1-4]. LEDs are solid-state devices that emit light, the wavelengths of which lie in narrow bands with high photon flux, which allows the manipulation of the spectral characteristics and intensity of the light. In general, LED chips convert about $50-70 \%$ of the input power into light, and the remaining power is dissipated as heat, depending on the operating junction temperature and efficiency. For instance, a typical industry standard LED grow light with $1 \mathrm{~kW}$ input power generates the equivalent of $1000-1500 \mathrm{~W} / \mathrm{m}^{2}$ heat flux on the LED circuit board depending on the design. Since operating LED grow lights at higher temperatures significantly reduces the efficiency and reliability of the LED chips, as well as causes chip failure, proper cooling of LED grow lights is a critical design requirement to maintain the high efficiency and reliability of the LED chips $[5,6]$. Therefore, the heat transfer must not cause the surface to exceed the maximum allowable 
temperature. This temperature has to be related to the LED junction temperature and may well change with time as LEDs generate more heat as they age, e.g., [5,6]. Thus, a reasonable level of conservatism is needed in heat sink design. In other words, the design for a new grow light should provide a maximum fin surface temperature somewhat below the allowable maximum.

Using computational fluid dynamics (CFD) and experiments, this paper develops a novel heat sink design for natural convection cooling of LED grow lights, which is found to significantly improve the heat transfer performance, as well as allow close control of the maximum surface temperature and can be implemented in cooling electronics whenever natural convection can be used. A limited CFD analysis was used by [6] to study cooling of LEDs, but few details were given and no comparison made to measured fin temperatures. We are unaware of any further CFD studies for LEDs.

Currently, almost all LED grow lights are cooled using forced convection air cooling. Fans remove the heat locally either by forcing air through the heat sinks mounted on the LED circuit boards or directly forcing air through the circuit board surface. As the convected warm air heats up the air around the plants, the indoor warm air is removed again through a large-scale air-conditioning system to maintain suitable indoor air temperature and humidity for the plant. Because fans consume a significant amount of power, as well as being points of failure and cost, they may not be the best method for cooling LED grow lights. Further, if fans are used, the LED grow lights are highly susceptible to damage from moisture, water, and dust. Failure of fans can lead to damage of LED chips or the grow light. As an alternative, natural convection cooling employing finned surfaces or heat sinks does not require any moving parts, and there is lower susceptibility of damage due to moisture and water ingression. However, a major design challenge with conventional natural convection cooling is that it has a relatively low heat transfer rate compared to forced convection cooling, practically limiting the cooling performance and reliability of LED grow lights. It is worth noting that for conventional fins, high heat transfer is associated with high surface temperature, which may exceed the component tolerance. Therefore, novel heat sink designs that can increase natural convection heat transfer without exceeding the component maximum temperature are highly desirable. Considering the typical heat flux, i.e., heat transfer per unit base surface area $Q / A_{b}$, of about $1000-1500 \mathrm{~W} / \mathrm{m}^{2}$ from the LED circuit board, efficient operating temperature limits of the LED chips, and currently available high-efficiency LED chips, a new heat sink design proposed here shows a promising cooling performance, as well as potential economic benefits for LED grow lights. The new heat sink is a rectangular array of straight fins with openings in the base as depicted in Figure 1. While a number of fin designs can be used with this design concept, the most commonly used rectangular array of straight fins on a horizontal surface is considered in this work. The results of this study show that the new design increases the vertical flow of air and hence the heat transfer. For the particular design investigated here, it was found that such a design can transfer more than $1075 \mathrm{~W} / \mathrm{m}^{2}$ within an efficient operating temperature range of LED chips, which is about $53 \%$ greater than the rectangular fins without openings in the base.

Natural convection cooling occurs due to buoyancy forces as a result of differential heating of air around the fin surfaces, and the heat transfer occurs across the thermal boundary layer [7-9]. A circulatory thermal flow field develops around the finned surfaces as a result of downward flow of cold air and upward flow of warm air. The upward and downward flow of air results in a vertical converging draft of air, commonly referred to as a "chimney" or "plume", on which the natural convection heat transfer relies [7,10-13]. As a consequence, the flow field exhibits a very complex three-dimensional fluid motion with heat transfer. Therefore, improved understanding of the flow and heat transfer characteristics around the finned surfaces is crucial to increase convection cooling. Incorrectly designed finned surfaces not only lead to lower heat transfer than the surfaces without fins, but also increase the footprint area and weight of the finned surfaces [10,11,14-17]. While a number of fin designs are available [18-21], the new heat sink design is based on the most commonly used rectangular array of straight fins on a horizontal surface, as depicted in Figure 1, which can be easily integrated into the design of LED grow lights. There are numerous studies on natural convection cooling of these fins $[10,11,19,22]$. Earlier experimental work of Jones and Smith [11] on rectangular 
fins on a horizontal surface showed that for the same height, length, and number of fins, the optimum fin spacing and array width transferred significantly more heat flux $Q / A_{b}$ than very narrow and wide fin arrays. This revealed that the width of the fin array or the fin spacing is an important parameter to maximize $Q / A_{b}$. The physical basis is that the flow of cooling air from the array sides, i.e., in the transverse direction or width-wise, is as important as the flow in the longitudinal direction from the channel ends. As the highest $Q$ is associated with the highest surface temperature [23], maximum temperature $T_{\max }$ is to be constrained, so alternative flow mechanisms are needed to achieve high $Q$. The design implication is that wider fin arrays should have openings in the base to increase downward flow of cooling air or from the array sides to maximize $Q / A_{b}$. This is due to the fact that in wider arrays, air flow from the array sides cannot reach the array center for cooling. To address this problem, a new heat sink based on rectangular straight fins with openings in the base was designed, which significantly increased vertical flow of cooling air around the fins and heat transfer. A related study was done by [24] on the heat sink with perforations in the fin base. They showed that perforations increased the heat transfer and air flow. As the heat flux in LED grow lights is significant, large openings are needed. Furthermore, due to the design requirements of LED grow lights, rectangular openings are suitable. The literature review revealed that there are no prior studies on the design of natural convection heat transfer from rectangular straight fins with large rectangular openings in the base, i.e., between the LED circuit boards, with specific applications to natural convection cooling of LED grow lights.

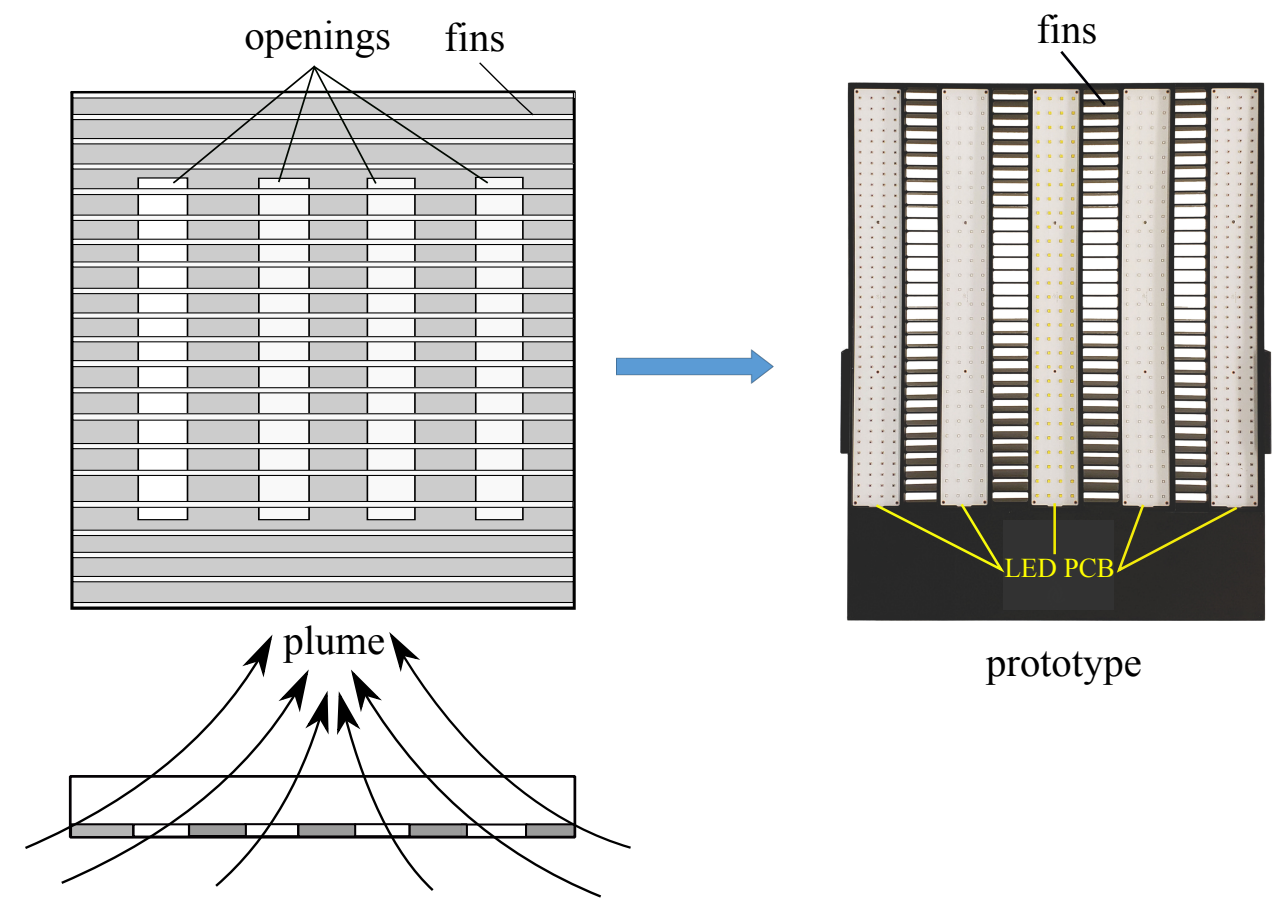

Figure 1. Schematic of the proposed rectangular array of straight fins with transverse openings in the base for natural convection cooling of LED grow lights (left) and a prototype LED grow light with the proposed heat sink (right). The black area in the right-hand figure represents the LED power electronics. The openings increase the vertical flow of air around the fins. Typically, the array is square with sides of about $500 \mathrm{~mm}$.

The paper is structured as follows. In the next section, the new heat sink design for natural convection cooling of LED grow lights is presented. Section 3 describes the numerical method used in the conjugate heat transfer simulations. Section 4 presents the results of heat transfer from optimum rectangular fins without openings and new heat sink design with openings in the base. 
Experimental results of the thermal performance of a prototype LED grow light with the new heat sink are presented. Finally, Section 5 summarizes the main conclusions.

\section{A Novel Heat Sink Design for Cooling Led Grow Lights}

In a typical LED grow light, hundreds of LEDs are mounted on a large circuit board to produce uniform light intensity over a large area. Moreover, the LED circuit board is mounted horizontally, which is particularly suited for designing a rectangular array of straight fins at the back surface of the circuit board. These features are advantageous for designing a natural convection cooling system as the heat sink can be mounted at the back of the LED circuit board or more conveniently designed as an enclosure for the LEDs and the associated driver circuit board. Exploiting these design features, a novel heat sink design based on a rectangular array of straight fins with multiple openings in the base is proposed, as shown in Figure 1. The novel feature of this design is the openings in the base to increase the vertical air flow around the fins, which results in improved heat transfer and allows the constraint on surface temperature to be applied without adversely affecting $Q$. The thermal performance of the new heat sink design was analyzed using numerical simulations and also experimentally measured for a prototype LED grow light. The proposed design is not only applicable to the specific case of a rectangular array of straight fins for natural convection cooling of LED grow lights, but also applicable to a wide range of heat sink configurations for natural convection cooling of high power LED lights, such as bay and street lights and concentrated photovoltaic systems [25].

\section{Computational Model and Validation}

We analyzed the conjugate heat transfer and flow characteristics using three-dimensional, steady state, laminar flow simulations with variable air properties. The simulations were conducted on the commercial computational fluid dynamics (CFD) code ANSYS Icepak-Fluent [26]. The governing equations are the conservation of mass, momentum, and energy for the flow and the heat conduction equation for the solid, which are written in Cartesian co-ordinates, with $x$ in the direction of the fins, $y$ the vertical, and $z$ in the transverse direction normal to the fins. The following equations are solved:

Continuity equation for the steady flow:

$$
\frac{\partial \rho u}{\partial x}+\frac{\partial \rho v}{\partial y}+\frac{\partial \rho w}{\partial z}=0
$$

Momentum equation:

$$
\begin{gathered}
u \frac{\partial \rho u}{\partial x}+v \frac{\partial \rho u}{\partial y}+w \frac{\partial \rho u}{\partial z}=-\frac{\partial p}{\partial x}+\frac{\partial}{\partial x}\left(\mu \frac{\partial u}{\partial x}\right)+\frac{\partial}{\partial y}\left(\mu \frac{\partial u}{\partial y}\right)+\frac{\partial}{\partial z}\left(\mu \frac{\partial u}{\partial z}\right) \\
u \frac{\partial \rho v}{\partial x}+v \frac{\partial \rho v}{\partial y}+w \frac{\partial \rho v}{\partial z}=-\frac{\partial p}{\partial y}+\frac{\partial}{\partial x}\left(\mu \frac{\partial v}{\partial x}\right)+\frac{\partial}{\partial y}\left(\mu \frac{\partial v}{\partial y}\right)+\frac{\partial}{\partial z}\left(\mu \frac{\partial v}{\partial z}\right)+\left(\rho-\rho_{0}\right) g \\
u \frac{\partial \rho w}{\partial x}+v \frac{\partial \rho w}{\partial y}+w \frac{\partial \rho w}{\partial z}=-\frac{\partial p}{\partial z}+\frac{\partial}{\partial x}\left(\mu \frac{\partial w}{\partial x}\right)+\frac{\partial}{\partial y}\left(\mu \frac{\partial w}{\partial y}\right)+\frac{\partial}{\partial z}\left(\mu \frac{\partial w}{\partial z}\right)
\end{gathered}
$$

Energy equation:

$$
u \frac{\partial T}{\partial x}+v \frac{\partial T}{\partial y}+w \frac{\partial T}{\partial z}=\frac{\partial}{\partial x}\left(\alpha \frac{\partial T}{\partial x}\right)+\frac{\partial}{\partial y}\left(\alpha \frac{\partial T}{\partial y}\right)+\frac{\partial}{\partial z}\left(\alpha \frac{\partial T}{\partial z}\right)+S
$$

where $S$ is the source term for radiation. The temperature distribution within the fins was computed by the steady state Laplacian with constant thermal diffusivity. In natural convection problems in fins, Rayleigh numbers $R a<10^{8}$ indicate a laminar flow, with transition to turbulence occurring over the range of $10^{8}<R a<10^{10}$ [26]. $R a$ is defined as $\rho \beta\left(T_{s}-T_{\infty}\right) L^{3} /(v \alpha)$, where $\rho$ is the air density, $\beta$ is the thermal expansion coefficient, $T_{S}$ is the fin surface temperature, $T_{\infty}$ is the ambient temperature, $L$ is 
the characteristic length of the fins, $v$ is the kinematic viscosity of air, and $\alpha$ is the thermal diffusivity. As $R a \approx 9.46 \times 10^{7}$ in the fins examined in this work, laminar flow was assumed. Radiative heat transfer was considered using the surface-to-surface radiation model [26-28]. For brevity, we do not show the model equations, which can be found in the references $[26,28]$. To account for the variation of air properties, such as density, viscosity, thermal conductivity, and diffusivity due to temperature changes, the ideal gas law was used with experimental data for the property variations. Viscosity $\mu$ was computed using Sutherland's law [13] as:

$$
\mu=1.45 \times 10^{-8} \frac{T^{3 / 2}}{T+110}
$$

where $T$ is expressed in degrees Kelvin and $\mu$ in $\mathrm{kg} / \mathrm{ms}$. Similarly, density is calculated from the ideal gas law as:

$$
\rho=\frac{p_{o p}}{\frac{R}{M} T}
$$

where $R$ is the universal gas constant and $p_{o p}$ is the operating atmospheric pressure. The variations of air properties with temperature used in the simulations are presented in Figure 2 of [23]. The computational domain was discretized with fully structured hexahedral grids with high resolution in the near wall region to capture the effects of the thermal boundary layer more accurately; see Figure 2. Opening type of boundary conditions were used at all sides of the computational domain with the buoyancy enabled, and ambient temperature and pressure were specified. The details of the numerical scheme and grid independence study are similar to the one reported in the reference [23] and are omitted here.

The computational model was validated against the measured heat transfer from rectangular fins on a horizontal surface without openings by Jones and Smith [11], which is possibly the most systematic experimental study available in the literature. The details of geometrical parameters and experimental results are available for different fin configurations, which allowed us to make comparisons between the CFD and experimental results and investigate the optimum fins for the new heat sink design. The details of the fin geometrical parameters and temperature variations in the experimental measurements used in the CFD simulations are summarized in Table 1. All the fin configurations tested by Jones and Smith [11] have length $L=254 \mathrm{~mm}$, fin thickness $t=3.17 \mathrm{~mm}$, and number of fins $n=7$. Only fin height $H$ and spacing $s$ were varied, and thus, the width of the fin array, $W$, was different for each $s$. In the measurements of Jones and Smith [11], average surface temperature and ambient temperature were considered to calculate the temperature difference. The temperature difference in the CFD calculations was based on the difference between the maximum temperature on the fin surface and the ambient temperature. To quantify the thermal performance of a particular fin design, $Q / A_{b}$ was used as in Jones and Smith [11]. The comparison of the CFD and the experimental results for $Q / A_{b}$ is shown in Figure 8 of [23]. A maximum relative error of about $11.34 \%$ was found between the experimental and CFD results, which is a fairly good agreement in view of the uncertainties incurred in both the experimental measurements and the numerical simulations. Jones and Smith's experimental results had about $\pm 10 \%$ uncertainty. Importantly, the computed $Q / A_{b}$ has its maximum at the same $s$ as the measurements, despite the difference in magnitude. The fundamental heat transfer characteristics and flow features relevant to the proposed heat sink design are briefly investigated in the next section.

Table 1. Fin design parameters of Jones and Smith [11] used in the simulations.

\begin{tabular}{ccccc}
\hline Length, $\mathbf{~ m m}$ & Height, $\mathbf{~ m m}$ & Spacing, $\mathbf{~ m m}$ & No. of Fins & Temperature Difference, ${ }^{\circ} \mathbf{C}$ \\
\hline 254 & 49.28 & $4.04,6.35,8.38,12.70,25.40,50.80$ & 7 & 151 \\
\hline
\end{tabular}




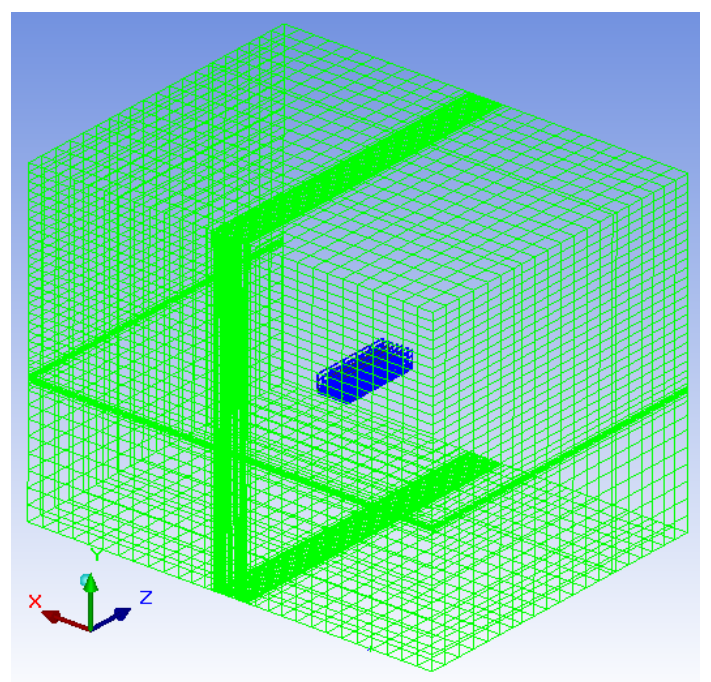

(a)

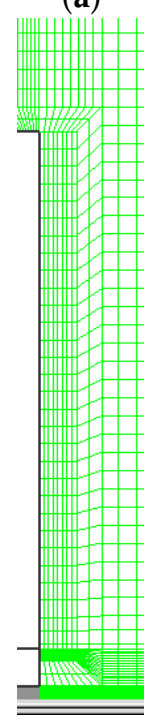

(b)

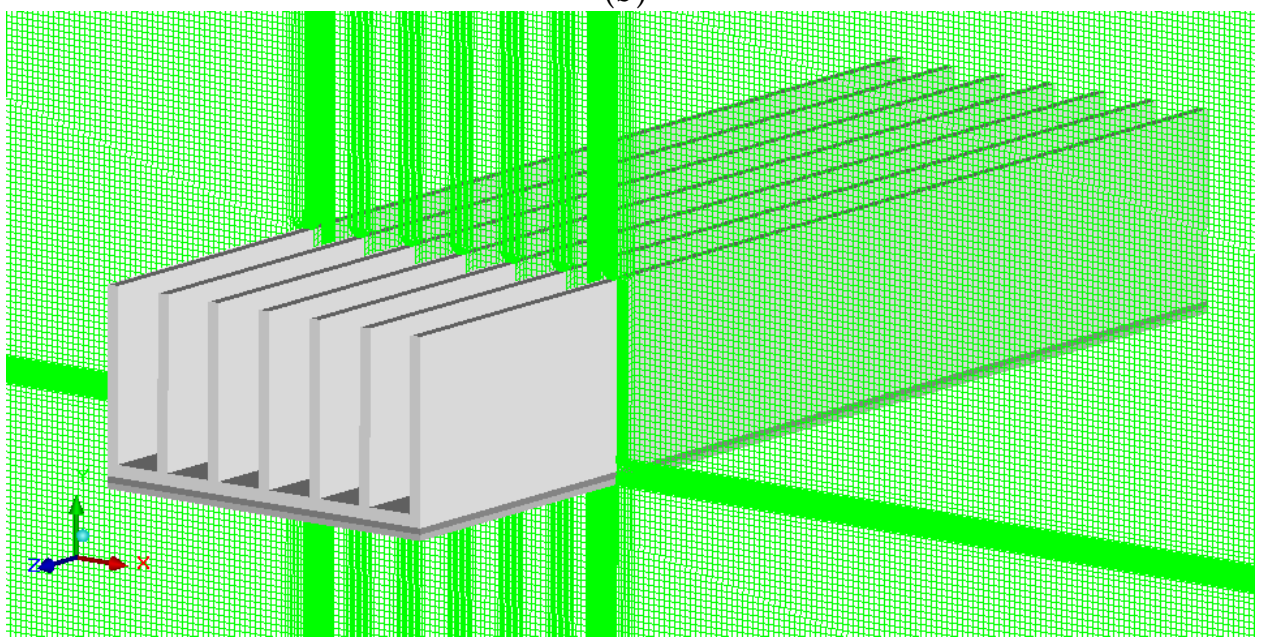

(c)

Figure 2. A three-dimensional hexahedral computational mesh used in the simulations (a). The blue region is the fin array. Zoomed views of a typical mesh resolution on the fin walls $(\mathbf{b})$ and a cross-section of the mesh around the fins (c). 


\section{Results and Discussion}

Results are presented in three parts. The first part investigates numerically the heat transfer characteristics of optimum rectangular straight fins without openings in the base and demonstrates the need for incorporating openings in the base in wider fin arrays to maximize heat transfer and limit the surface temperature. The second part analyzes the heat transfer performance of the new heat sink design numerically, and preliminary design data for the heat sink of the prototype LED grow light are developed. The third part presents the numerical and experimental results on the heat transfer performance of the new heat sink in the prototype LED grow light.

\subsection{Heat Transfer Characteristics of Optimum Fins}

Figure 8 of [23] shows that maximum heat transfer per unit base area $Q / A_{b}$ occurs within a narrow range of fin spacing, $s_{\text {opt }}=6-8 \mathrm{~mm}$, for the same $n, H$, and $L$. In natural convection, the velocity field is coupled with the temperature field. It is shown in Figure 8b of Adhikari et al. [23] that a three-dimensional converging vertical flow is developed above the center of the fin array as a result of horizontal inflow of air from the channel ends and the array sides. This type of flow is called a "chimney" or "plume". It is shown that the plume in the transverse direction of the optimum fins converged into a narrower plume in comparison to the array width. In contrast to this, the plume for $s=50.8 \mathrm{~mm}$ in the transverse direction, shown in Figure 3, is of comparable size with the array width. This reveals that in addition to the flow in the longitudinal direction from channel ends, the converging plume in the transverse direction is important for maximizing $Q / A_{b}$. Although the air flow patterns from the channel ends toward the array center and plumes are similar in both cases, the array width significantly reduces the air flow from the sides, and hence the heat transfer. Without sufficient air flow around the array center converging into a plume, the heat transfer would decrease. Since LED grow lights have a large surface area and are mounted horizontally, it follows that incorporating openings in the base allows vertical air flow, which should increase $Q / A_{b}$. This specific heat transfer characteristic forms the basis for designing the rectangular straight fins with openings in the base as a heat sink for natural convection cooling of the LED circuit board of grow lights.
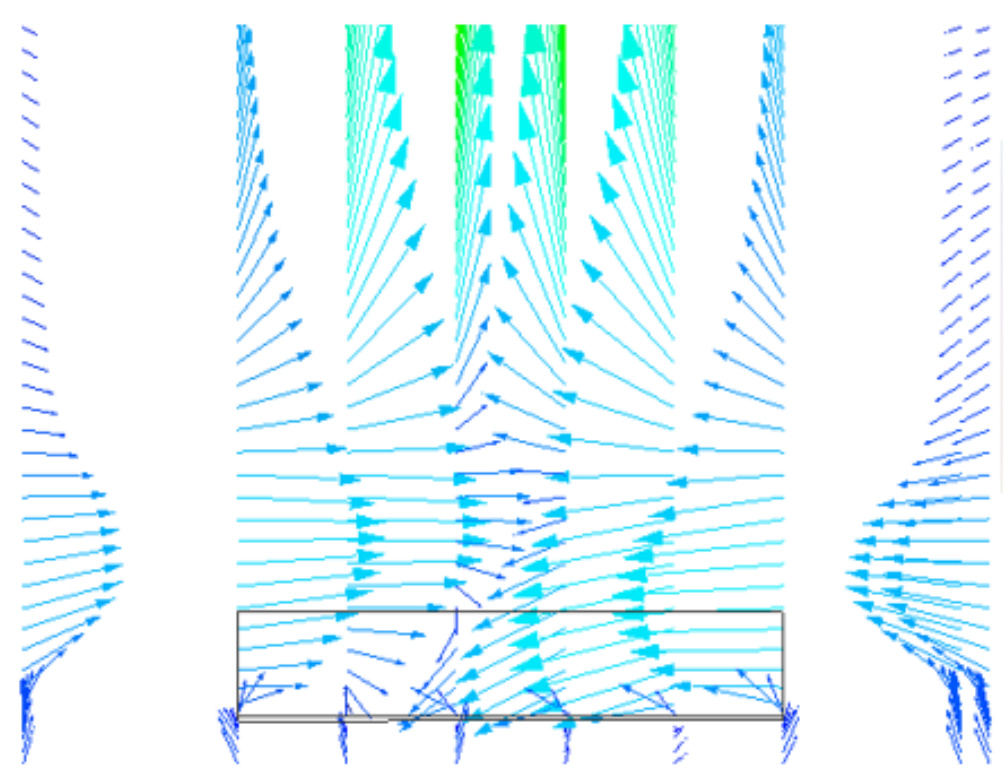

(a)

Figure 3. Cont. 


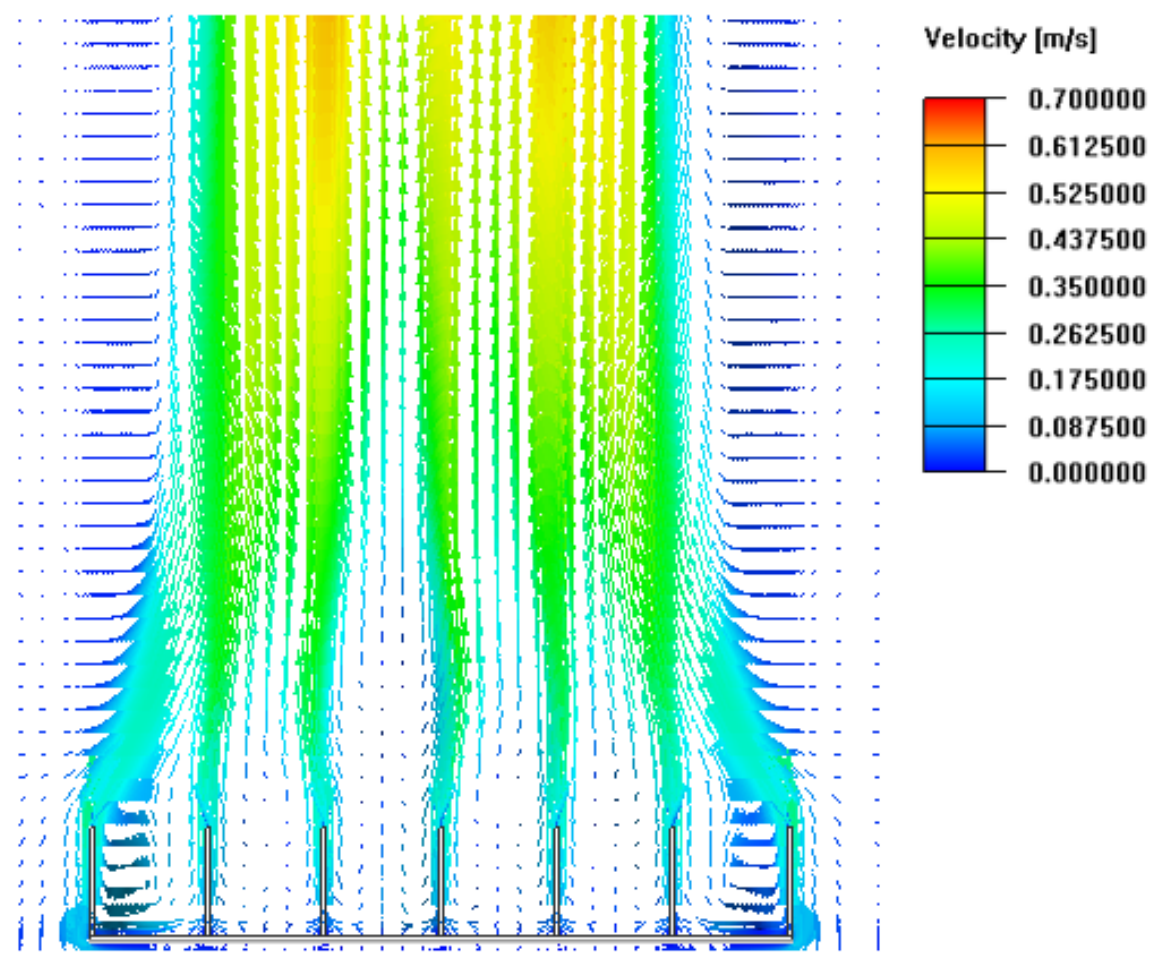

(b)

Figure 3. Velocity vectors plotted at the mid-plane in the fin channel with surface openings in the longitudinal direction (a) and the transverse direction (b) at fin spacing $s=50.8 \mathrm{~mm}$, illustrating the effects of large array width on the plume structure ( $L=254 \mathrm{~mm}, H=49.28 \mathrm{~mm}, n=7$, and $\left.\Delta T=151{ }^{\circ} \mathrm{C}\right)$.

\subsection{Design and Numerical Analysis of the New Heat Sink}

As LED grow lights require long and wide circuit boards, improving the vertical flow of air around the fins mounted at the back of the circuit board is crucial to increase $Q / A_{b}$. In addition, there are limits on the allowable component temperature, so increased $Q / A_{b}$ must be constrained by a limit on the surface temperature. As discussed above, the design concept is to incorporate multiple openings in the base as depicted in Figure 4. It is evident that the openings effectively reduce a large array into multiple and narrow fin arrays, which forms the basis for improved $Q / A_{b}$. In a wider fin array, openings improve the vertical flow of air around the fins, and thus increase heat transfer. To investigate the thermal performance of the new heat sink with openings, simulations were performed on designs without and with openings in the base, as shown in Figure 4. The heat sink was designed for an LED grow light prototype with LED surface area $512 \mathrm{~mm} \times 512 \mathrm{~mm}$ for dissipating at least $250 \mathrm{~W}$ of heat with the maximum temperature, specified as $T_{\max }=60^{\circ} \mathrm{C}$, which falls within an efficient operating range of LED chips. The length $L$, width $W$, and fin height $H$ of the heat sink were initially chosen as $512 \mathrm{~mm}, 512 \mathrm{~mm}$, and $40 \mathrm{~mm}$, respectively, based on the dimensions of the prototype LED grow light. As a preliminary design, the optimum fin spacing $s_{\text {opt }}=9 \mathrm{~mm}$ was calculated using the correlation, $H s=360 \mathrm{~mm}^{2}$, as suggested by Jones and Smith [11], for optimum fins of height $H=49.28 \mathrm{~mm}$, length $L=254 \mathrm{~mm}$, and thickness $t=3.17 \mathrm{~mm}$, analyzed in the previous section. To determine an optimum range of fin spacing $s_{o p t}$ for maximum $Q / A_{b}$, simulations were performed for $n=25,30,35,40$, and 45 with and without openings in the base. The opening length $L_{0}$ and width $W_{0}$ were chosen as $500 \mathrm{~mm}$ and $42 \mathrm{~mm}$, respectively, based on the LED circuit board dimensions and were kept constant for all simulations. For the heat sink of the prototype LED grow light, the main design objective was to maximize $Q / A_{b}$ for minimum fin weight while limiting $T_{\max }$. Only $s$ or $n$ was optimized as it affects $Q / A_{b}$ per unit weight, and the other parameters were held constant as per the design specifications of 
the prototype LED grow light. The preliminary design parameters for the heat sink of the LED grow light prototype are summarized in Table 2.

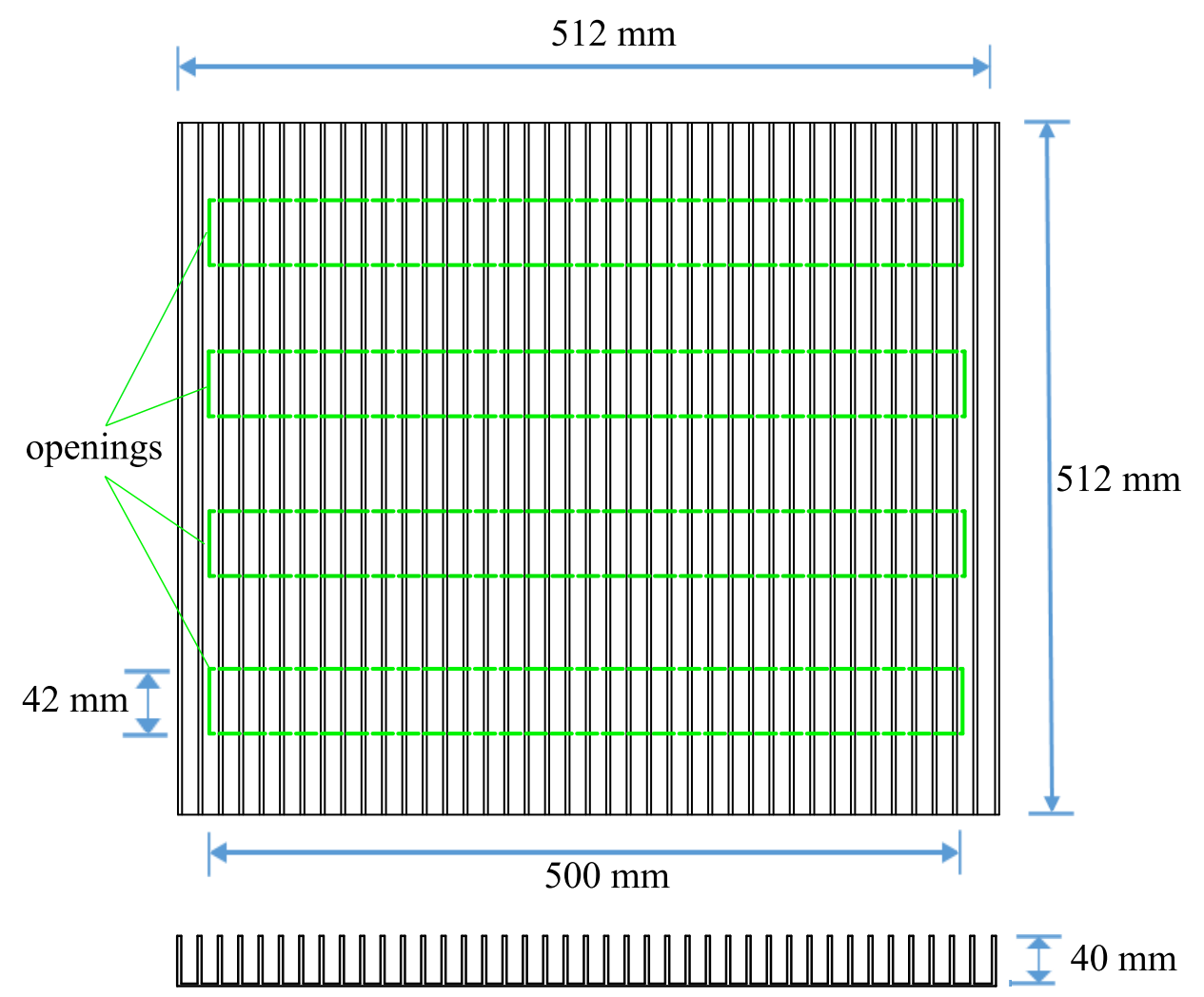

Figure 4. The new heat sink design with openings in the base for the prototype LED grow light.

Table 2. Design parameters of the new heat sink.

\begin{tabular}{ccc}
\hline Parameters & Without Openings & With Openings \\
\hline Fin length, $L(\mathrm{~mm})$ & 512 & 512 \\
\hline Array width, $W(\mathrm{~mm})$ & 512 & 512 \\
\hline Fin height, $H(\mathrm{~mm})$ & 40 & 40 \\
\hline Fin spacing, $s(\mathrm{~mm})$ & $8-14$ & $8-14$ \\
\hline Fin thickness, $t(\mathrm{~mm})$ & 2 & 2 \\
\hline Number of fins, $n$ & $25-45$ & $25-45$ \\
\hline Opening length, $L_{0}(\mathrm{~mm})$ & - & 500 \\
\hline Opening width, $W_{0}(\mathrm{~mm})$ & - & 42 \\
\hline Number of openings & - & 4 \\
\hline Maximum fin temperature, $T_{S}\left({ }^{\circ} \mathrm{C}\right)$ & 60 & 60 \\
\hline Ambient temperature, $T_{\infty}\left({ }^{\circ} \mathrm{C}\right)$ & 20 & 20 \\
\hline
\end{tabular}

The results for $Q / A_{b}$ without and with openings in the base are shown in Figure 5, which shows that openings significantly increased $Q / A_{b}$. For the specific design case investigated here, openings increased $Q / A_{b}$ by about $53.4 \%$. It can be observed that the optimum fin spacing $s_{\text {opt }}$ for the case with openings is smaller than the fin array without openings. The reason for this is that wider fin spacing in the base without openings allows more air from the channel ends. The temperature contours without and with openings for the cases of optimum fin spacing $s_{\text {opt }}$ are plotted in Figures 6 and 7, respectively. 
The corresponding velocity vectors without and with openings for the cases of optimum fin spacing $s_{\text {opt }}$ are plotted in Figure 8. It can be observed that air flows from the channel ends converge into a narrow plume above the array center, whereas in the transverse direction, two separate plumes above the center can be observed. As discussed above, air flows from the array sides of the wider array could not reach the array center and converge into a single narrow plume, resulting in a reduction in heat transfer. For the same array with openings, Figure 7 shows that the plume in the longitudinal direction is similar to the one without openings, but in the transverse direction, multiple smaller plumes separated by the openings converge into a single plume above the center, resulting in a significant increase in heat transfer. It is noted that the temperature at the center of each opening is close to ambient, increasing heat transfer. Furthermore, the openings increase the air velocity in the plume, a desirable requirement for improving heat transfer in natural convection. The air flow from the array sides is lower than in the case without openings. It is noteworthy that the openings create a wider plume cross-section above the fin array due to vertical flow of air through the openings. In contrast to the array without openings, the cool air first flows from the array sides toward the array center, then gets heated, and finally, convects upward as a narrow plume. This indicates that the openings achieved the design requirements with a margin of safety on the surface temperature. The temperature distributions at mid-height of fins, i.e., close to the boundary layers, in the longitudinal and the transverse directions are plotted in Figure 9, which shows that the temperature distributions in the plume in the longitudinal direction (a) in both cases are similar, whereas the temperature at the center of the openings in the transverse direction is close to ambient (b), increasing $Q / A_{b}$.

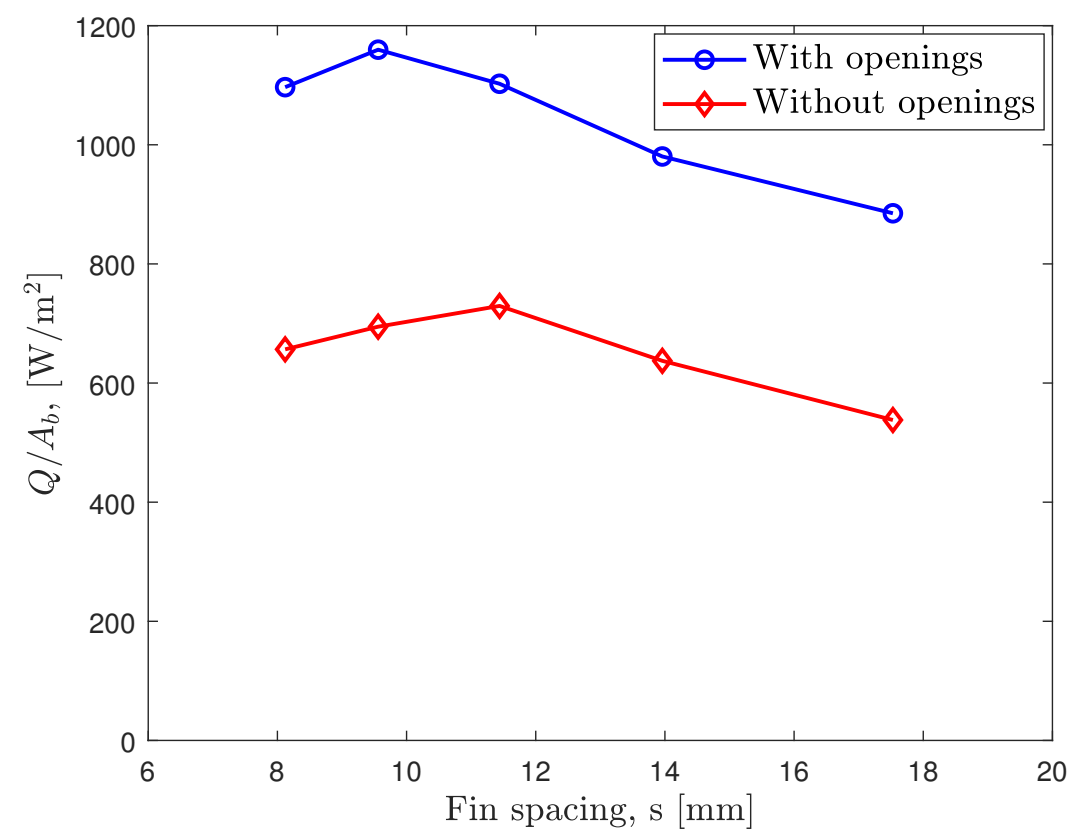

Figure 5. Comparison of heat transfer characteristics of straight rectangular fins with and without openings in the base $\left(L=512 \mathrm{~mm}, W=512 \mathrm{~mm}, H=40 \mathrm{~mm}, t=2 \mathrm{~mm}\right.$, and $\left.\Delta T=40^{\circ} \mathrm{C}\right)$. 

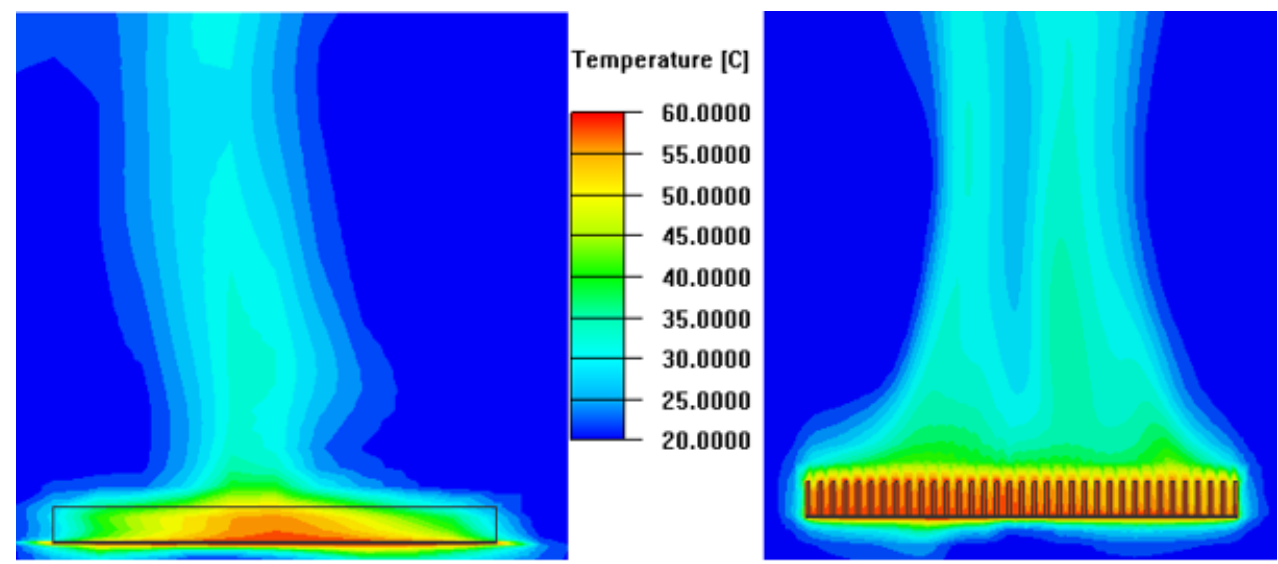

Figure 6. Temperature contours taken at the mid-plane in the longitudinal (left) and transverse (right) directions without openings in the base $(L=512 \mathrm{~mm}, W=512 \mathrm{~mm}, t=2 \mathrm{~mm}, \mathrm{~s}=9.56 \mathrm{~mm}$, and $\left.\Delta T=40^{\circ} \mathrm{C}\right)$.
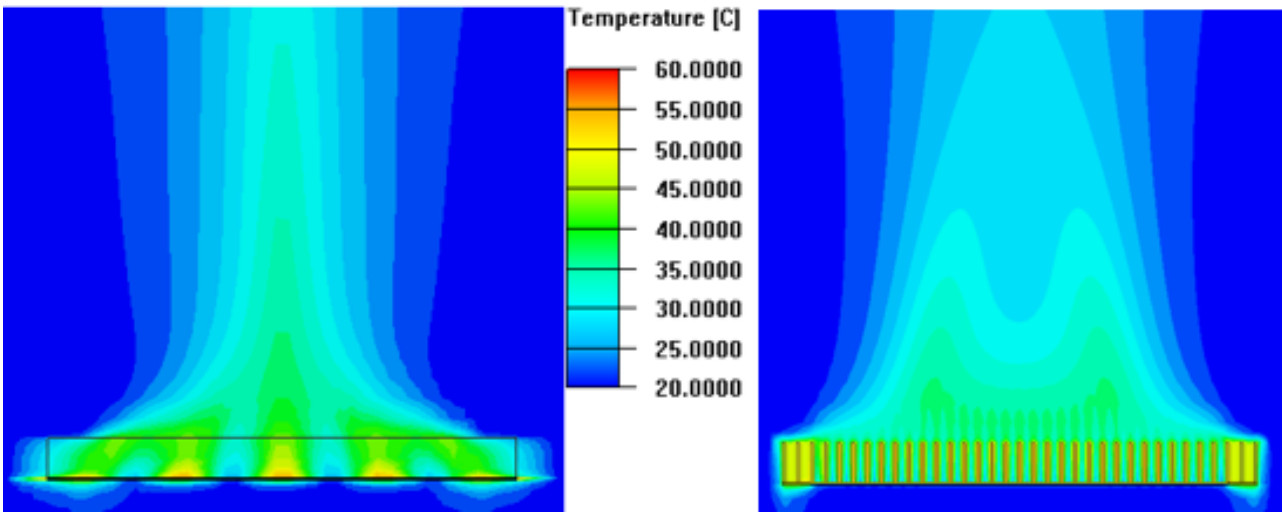

Figure 7. Temperature contours taken at the mid-plane in the longitudinal direction (left) and at an opening in the transverse direction (right) of the rectangular fins with openings at the base, illustrating vertical air flow through the openings ( $L=512 \mathrm{~mm}, W=512 \mathrm{~mm}, H=40 \mathrm{~mm}$, and $\Delta T=40^{\circ} \mathrm{C}$ ).
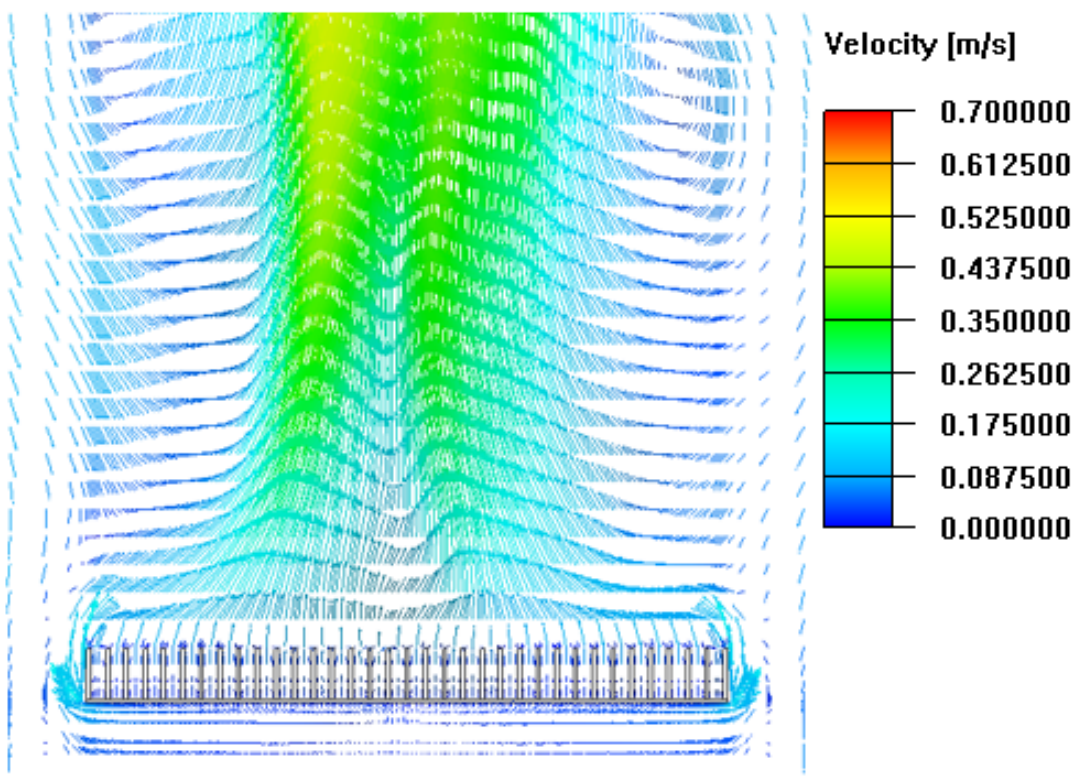

(a)

Figure 8. Cont. 


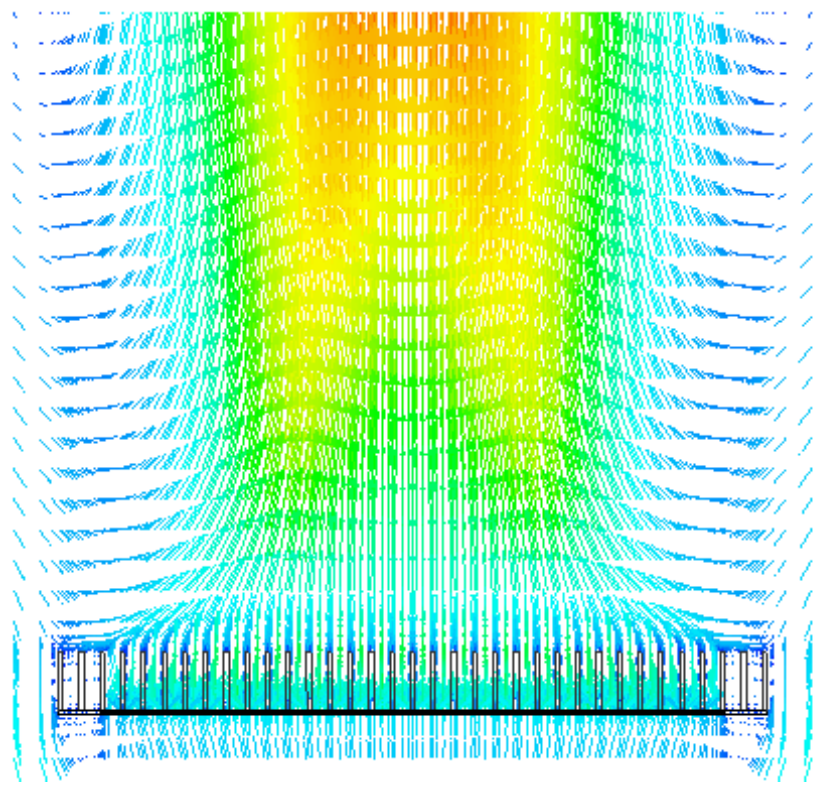

Velocity $[\mathrm{m} / \mathrm{s}]$

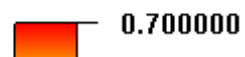

0.612500

0.525000

0.437500

0.350000

0.262500

0.175000

0.087500

0.000000

(b)

Figure 8. Velocity vectors plotted at the mid-plane in the fin channel without openings (a) and with openings (b) in the transverse direction, illustrating the vertical flow of air through openings and the plume structure $\left(L=512 \mathrm{~mm}, W=512 \mathrm{~mm}, H=40 \mathrm{~mm}\right.$, and $\left.\Delta T=40^{\circ} \mathrm{C}\right)$.

(a)

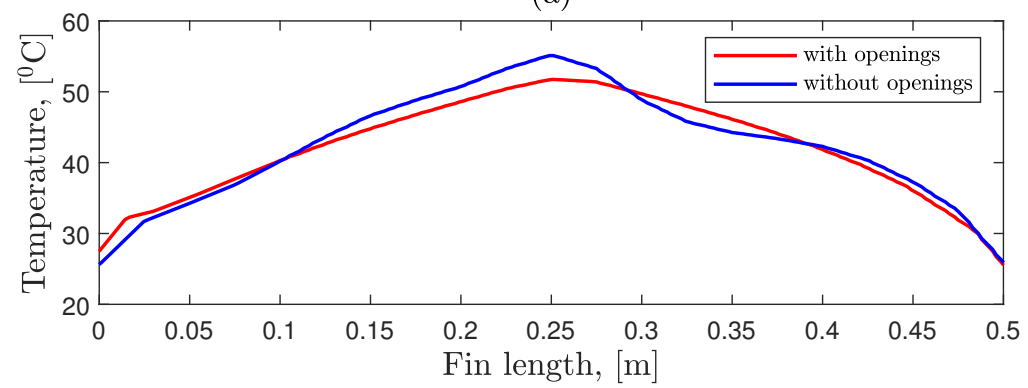

(b)

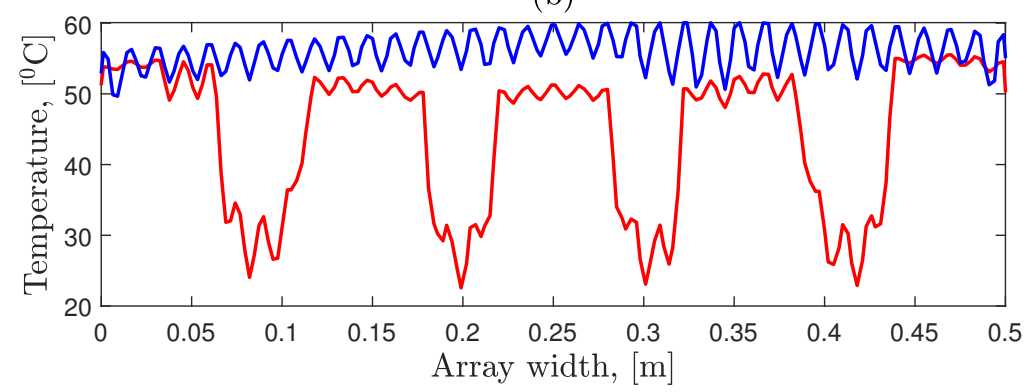

Figure 9. Temperature profile at mid-height along the fin channel at the mid-section of the optimum fin arrays with and without openings at the base (a) and along the transverse direction or width-wise (b). The minimum temperature in (b) indicates the openings ( $L=512 \mathrm{~mm}, W=512 \mathrm{~mm}, H=40 \mathrm{~mm}$, and $\left.\Delta T=40^{\circ} \mathrm{C}\right)$.

\subsection{Testing of the New Heat Sink}

To assess the functionality and thermal performance of the new heat sink, the optimum heat sink design analyzed in the previous section was implemented on a full-scale prototype LED grow light, as depicted in Figure 10. The heat sink was designed as an enclosure for the LED circuit boards and 
the power electronics with fin height $H=40 \mathrm{~mm}$ and spacing $s=12.85 \mathrm{~mm}$ on the top of LED surface and four openings in the base. The fin spacing was chosen based on the weight constraint of the prototype and is close to the optimum spacing $s_{\text {opt }}$. The openings have dimensions $500 \mathrm{~mm} \times 42 \mathrm{~mm}$. No search for optimal opening dimensions was made because the initial ones achieved the design requirements with a margin of safety on the surface temperature as discussed in the previous section. This margin is needed because the surface temperature may deviate from the LED junction temperature and grow lights need more cooling as they age. Five aluminum LED circuit boards of dimensions $504 \mathrm{~mm} \times 62 \mathrm{~mm}$ were bonded to the base surface of the heat sink with a thin layer of high thermal conductivity potting material with thermal conductivity, $K_{p}=2.16 \mathrm{~W} / \mathrm{mK}$. Each circuit board generates $50 \mathrm{~W}$ at maximum rated power input. As there are over 100 LEDs placed on a uniform grid on each circuit board, which is made of aluminum, the heat flux was assumed uniform.

The overall dimensions of the LED area of the grow light are $512 \mathrm{~mm} \times 512 \mathrm{~mm}$. The grow light also contains a power module with dimensions $120 \mathrm{~mm} \times 512 \mathrm{~mm}$ as part of the enclosure, and the top surface consists of shallow fins with $H=8 \mathrm{~mm}$. This module generates $32 \mathrm{~W}$ and is placed at $6 \mathrm{~mm}$ from the enclosure top surface. The spacing is potted with a high thermal-conductivity epoxy potting material with thermal conductivity, $K_{p}=2.16 \mathrm{~W} / \mathrm{mK}$. All the design conditions were considered in the conjugate heat transfer simulations. Very small design features of the fins, such as fillets and round corners in the fins, were omitted in the geometry to reduce the number of grid elements, the complexity of grid generation, and the computational time. The design specifications of the prototype LED grow light and the heat sink used in the simulations are summarized in Figure 10.

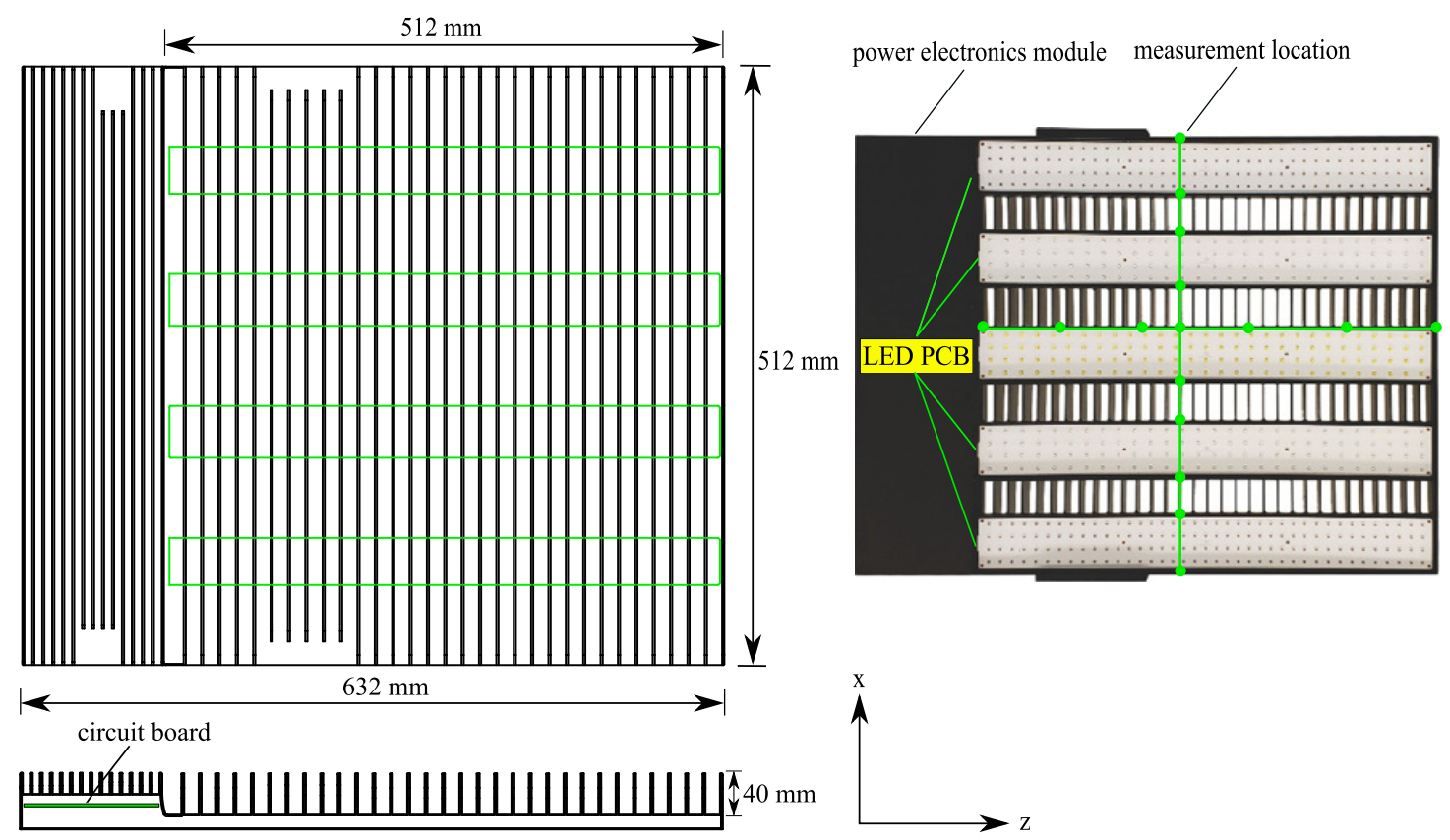

Figure 10. New heat sink enclosure (left) for the prototype LED grow light (right). The green circles represent the locations of temperature measurement.

The experimental measurement of the LED grow light was conducted in a large room with stagnant air, and the room temperature was constant at $20.7^{\circ} \mathrm{C}$ during the experiment. The experimental setup is shown in Figure 11. There were no obstacles in the immediate vicinity above and below the grow light in order to ensure that natural convection flow, particularly the plume, was not obstructed. The experiment was conducted at rated input power, which maximizes the surface temperature. The surface temperature of the heat sink $T_{S}$ at mid-sections of the base in the longitudinal and transverse directions was measured using an FLIR E75 thermal imaging camera. The maximum 
measurement error of the thermal camera was $\pm 2 \%$. The temperature was recorded after the heat sink attained a steady state surface temperature.

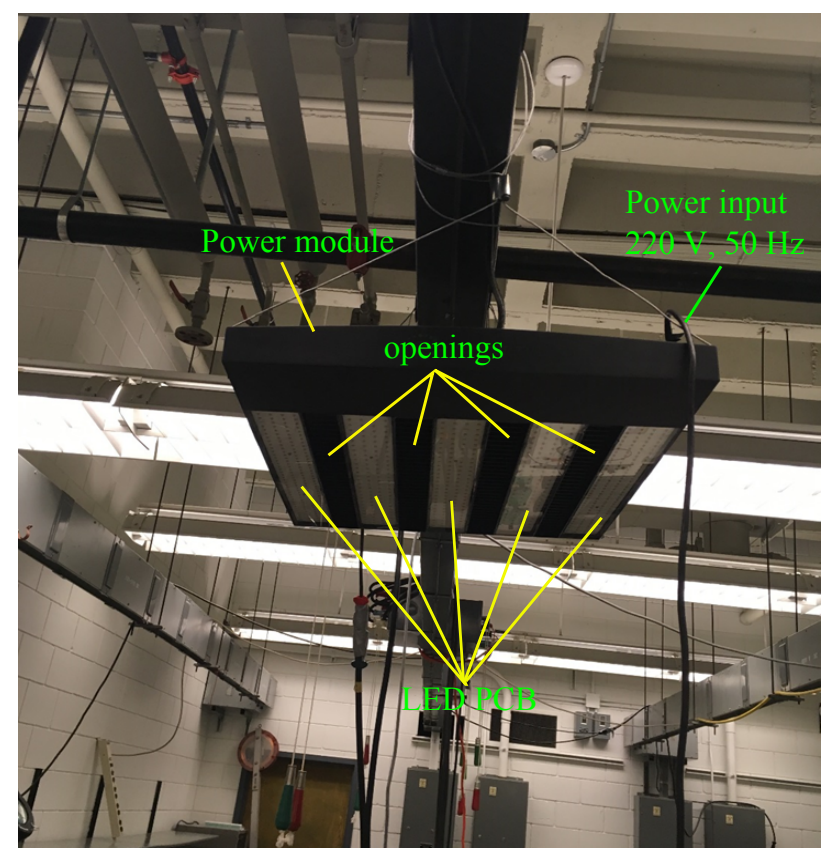

Figure 11. Experimental setup for the natural convection heat transfer of the prototype LED grow light shown in Figure 10.

A comparison of the experimental and the numerical results for the base surface temperature $T_{S}$ is shown in Figure 12. A good agreement was found between the two with about 4.53\% relative error. It is noted that for the experimentally tested case, the actual heat dissipation by the LED chips and the power converter module is lower, $Q_{e}=240 \mathrm{~W}$, than that assumed in the design, $Q_{d}=282 \mathrm{~W}$. In the legend of Figure 13, these are labeled "CFD-design case" and "CFD-experimental case", respectively. It is evident that the base surface temperature is approximately uniform, and the numerical simulation predicted the experimental data quite accurately. At maximum power input, the maximum measured temperature rise was $\Delta T=33.4^{\circ} \mathrm{C}$, which is lower than the design, $\Delta T=40^{\circ} \mathrm{C}$. This indicates that the heat sink can transfer more heat if the maximum temperature increases to the limiting value of $60{ }^{\circ} \mathrm{C}$. However, the experiment was limited to the maximum input power of the power module of the grow light. Considering a good agreement between the experiment and the simulation results, the new heat sink can transfer more than $1075 \mathrm{~W} / \mathrm{m}^{2}$ within the safe operating temperature of LED chips. It is observed from Figure 13 that the plume structures in the longitudinal and transverse directions are similar to the heat sink analyzed separately in the previous section. The velocity vectors plotted in Figure 14 show that the openings allowed the vertical air flow around the fins to converge into a single plume, which is the main mechanism for increased heat transfer. The results demonstrate that the openings significantly improve the heat transfer rate and can be used in natural convection cooling of LED grow lights for applications to indoor agriculture, which is expected to be the next generation agricultural technology. Further, the new design can be easily incorporated into many microelectronics and light enclosures, where natural convection cooling can be used. It is worth pointing out that further research is recommended to determine the generalized design correlations, which would be useful for design purposes. 
(a)

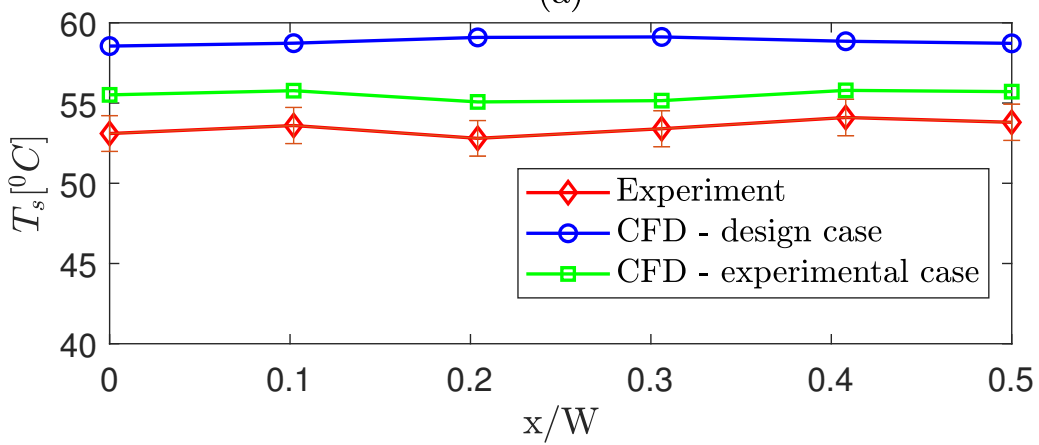

(b)

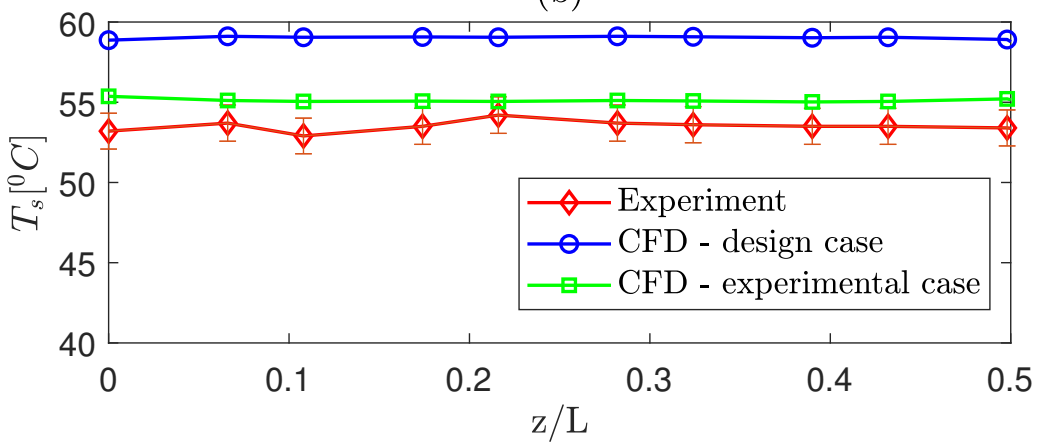

Figure 12. Comparison of the numerical and experimental results for the base temperature of the heat sink taken in the transverse (a) and longitudinal (b) directions above the LED circuit board. The measurement locations and directions are shown in Figure 10. The error bars on the measurements correspond to the manufacturer's stated accuracy of $\pm 2 \%$ for the thermal camera (For the design case, $Q_{d}=282$ Watts and for the experiment, $Q_{e}=240$ Watts).
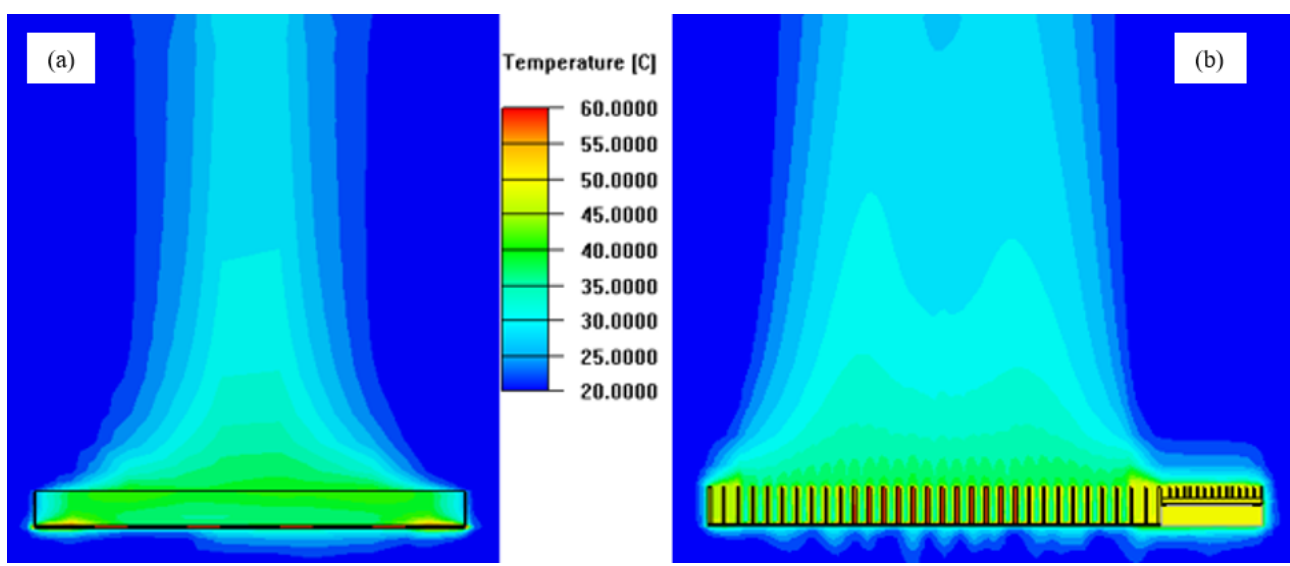

Figure 13. Temperature contours plotted at the array center along the mid-section of the fin channel (a) and at the center of opening along the transverse direction (b) of the LED grow light $(H=40 \mathrm{~mm}$, $s=12.85 \mathrm{~mm}$, and $\left.Q_{e}=240 \mathrm{~W}\right)$. 


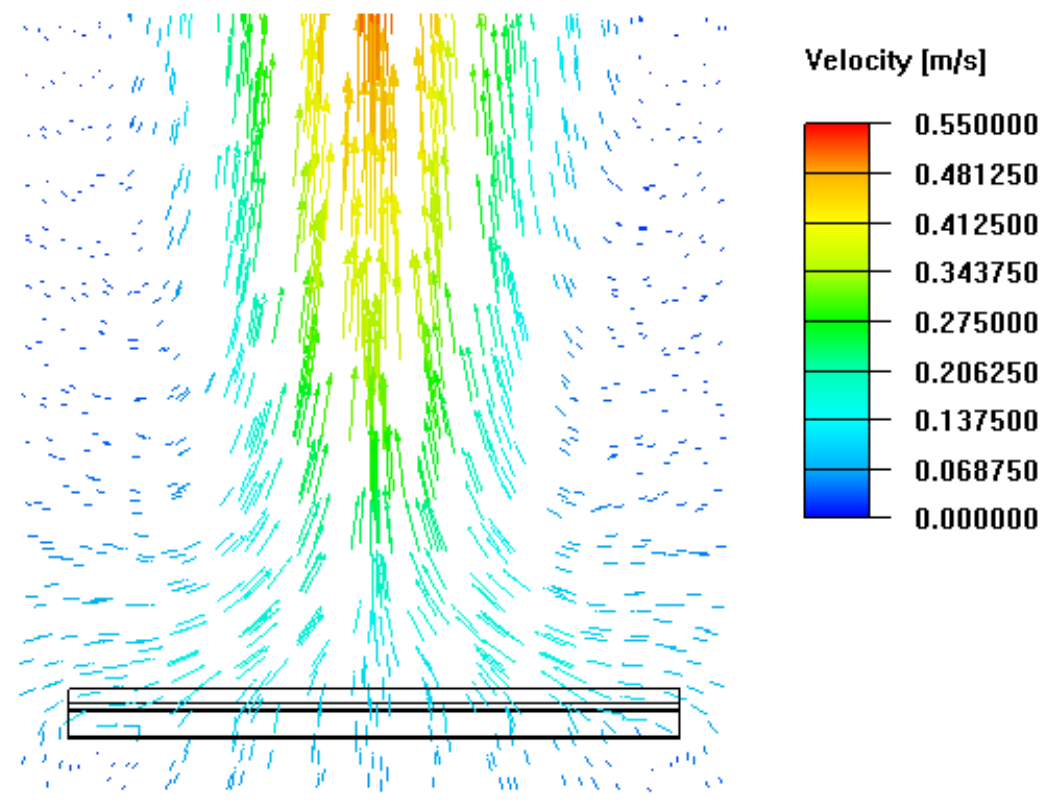

Figure 14. Velocity vectors plotted at the array center along the mid-section of the fin channel transverse to the openings of the LED grow light, illustrating the vertical flow of air through the openings and converging into a plume $\left(H=40 \mathrm{~mm}, s=12.85 \mathrm{~mm}\right.$, and $\left.Q_{e}=240 \mathrm{~W}\right)$.

\section{Conclusions}

A novel heat sink design based on rectangular straight fins with openings in the base for natural convection cooling of LED grow lights is presented. Significant improvement in natural convection heat transfer was found by incorporating openings in the base of a rectangular array of straight fins. The heat sink can be mounted on top of the LED circuit board as an enclosure for natural convection cooling of the circuit board. Three-dimensional, steady state laminar flow, conjugate heat transfer simulations, and experiments were conducted on a prototype LED grow light to assess the thermal performance of the new heat sink. The results of conjugate heat transfer simulations of a rectangular fin array without openings in wider fin arrays showed that the air flow from the array sides toward the center decreased considerably, resulting in a significant decrease in heat transfer. To improve air flow around the fins and the array center, openings were made in the base of the same fin array, which considerably improved the vertical air flow and heat transfer. Based on these findings, a prototype LED grow light with the new heat sink design was fabricated and experimentally tested for thermal performance.

Measurements of the base temperature of a prototype LED grow light agreed with the simulations to within a relative error of $4.53 \%$. The measured temperatures were about $5{ }^{\circ} \mathrm{C}$ lower than the assumed allowable maximum temperature of the base of the heat sink, which introduces a desirable conservatism in the design. This was needed as the base temperature may differ from the LED junction temperature and LED grow lights produce more heat as they age. Further, the need for conservatism suggests that an aggressively optimized design of the heat sink for a new grow light may become ineffective with time. The experimental results showed that openings significantly increased natural convection heat transfer. For a typical industry standard size of LED grow light investigated here, it is shown that more than $1075 \mathrm{~W} / \mathrm{m}^{2}$ heat transfer can be achieved with natural convection cooling within an efficient operating temperature range of LED chips. Therefore, the new heat sink design can be used for natural convection cooling of LED grow lights that are expected to be the main technology of the next-generation horticulture industry. Further, the new design can be easily incorporated in many microelectronics and light enclosures, where natural convection cooling can be 
used. Finally, it is worth pointing out that further research is recommended to investigate the influence of openings on heat transfer, and generalized design correlations would be particularly useful for practical design applications.

Author Contributions: R.A., D.B., and M.P. conceived of, designed, and tested the LED grow light heat sink. R.A. performed the conjugate heat transfer simulations, and D.W. and R.A. analyzed the numerical results. R.A. and D.B. tested the heat sink. All authors analyzed and synthesized the findings of the simulation and experimental results. All authors read and agreed to the published version of the manuscript.

Funding: This research received funding from Genoptic LED Inc, Canada.

Acknowledgments: The authors would like to acknowledge Genoptic LED Inc, Canada, for providing financial support for this project and CMC Microsystems Canada for providing the ANSYS license to perform heat transfer simulations.

Conflicts of Interest: The authors declare no conflict of interest.

\section{Abbreviations}

The following abbreviations are used in this manuscript:

CFD Computational fluid dynamics

RANS Reynolds-averaged Navier-Stokes

3D Three-dimensional

\section{Nomenclature}

$A_{b} \quad$ Base surface area of the fin array $(=n t L+(n-1) s L), \mathrm{m}^{2}$

$\alpha \quad$ Thermal diffusivity of air, $\mathrm{m}^{2} / \mathrm{s}$

$\beta \quad$ Coefficient of thermal expansion of air $\left(=1 / T_{f}\right), 1 / \mathrm{K}$

$H \quad$ Fin height, $\mathrm{mm}$

K Thermal conductivity of the fin $(=167 \mathrm{~W} / \mathrm{mK})$

$K_{p} \quad$ Thermal conductivity of the adhesive, $\mathrm{W} / \mathrm{mK}$

$L \quad$ Fin length, $\mathrm{mm}$

$L_{o} \quad$ Opening length, $\mathrm{mm}$

$n \quad$ Number of fins

Q Total heat transfer, $\mathrm{W}$

$R a \quad$ Rayleigh number $\left(=g \beta \Delta T l_{c}^{3} / \alpha v\right)$

$s \quad$ Fin spacing, $\mathrm{mm}$

$t \quad$ Fin thickness, $\mathrm{mm}$

$T \quad$ Fin surface temperature, ${ }^{\circ} \mathrm{C}$ or $\mathrm{K}$

$T_{\infty} \quad$ Ambient temperature, ${ }^{\circ} \mathrm{C}$ or $\mathrm{K}$

$T_{f} \quad$ Film temperature, $\left(T_{\infty}+T_{s}\right) / 2{ }^{\circ} \mathrm{C}$ or $\mathrm{K}$

$\Delta T$ Temperature difference between the fin surface and ambient temperatures, $\left(T_{S}-T_{\infty}\right){ }^{\circ} \mathrm{C}$ or $\mathrm{K}$

$u \quad$ Air velocity in the $\mathrm{x}$-direction, $\mathrm{m} / \mathrm{s}$

$v$ Air velocity in the $\mathrm{y}$-direction, $\mathrm{m} / \mathrm{s}$

$v \quad$ Kinematic viscosity of air, $\mathrm{m}^{2} / \mathrm{s}$

$w \quad$ Air velocity in the $\mathrm{z}$-direction, $\mathrm{m} / \mathrm{s}$

$W \quad$ Width of the fin array, $\mathrm{mm}$

$W_{o} \quad$ Width of the opening, $\mathrm{mm}$

$\rho \quad$ Density of the fin material, $\mathrm{kg} / \mathrm{m}^{3}$ 


\section{References}

1. Specht, K.; Siebert, R.; Hartmann, I.; Freisinger, U.B.; Sawicka, M.; Werner, A.; Thomaier, S.; Henckel, D.; Walk, H.; Dierich, A. Urban agriculture of the future: an overview of sustainability aspects of food production in and on buildings. Agric. Hum. Values 2014, 31, 33-51. [CrossRef]

2. Xu, Y.; Chang, Y.; Chen, G.; Lin, H. The research on LED supplementary lighting system for plants. Optik 2016, 127, 7193-7201. [CrossRef]

3. Song, J.W. Grow light for plant factory using quantum dot LED. J. Int. Counc. Electr. Eng. 2016, 6, 13-16. [CrossRef]

4. Benke, K.; Tomkins, B. Future food-production systems: vertical farming and controlled-environment agriculture. Sustain. Sci. Pract. Policy 2017, 13, 13-26. [CrossRef]

5. Hegedüs, J.; Hantos, G.; Poppe, A. Lifetime Modelling Issues of Power Light Emitting Diodes. Energies 2020, 13, 3370. [CrossRef]

6. Baran, K.; Różowicz, A.; Wachta, H.; Różowicz, S. Modeling of Selected Lighting Parameters of LED Panel. Energies 2020, 13, 3583. [CrossRef]

7. Kays, W.M. Convective Heat and Mass Transfer; Tata McGraw-Hill Education: New York, NY, USA, 2012.

8. Lienhard, J.H. A Heat Transfer Textbook; Courier Corporation: North Chelmsford, MA, USA, 2013.

9. Khatami, S.; Rahbar, N. An analytical study of entropy generation in rectangular natural convective porous fins. Therm. Sci. Eng. Prog. 2019, 11, 142-149. [CrossRef]

10. Starner, K.; McManus, H. An experimental investigation of free convection heat transfer from rectangular-fin arrays. J. Heat Transf. 1963, 85, 273-277. [CrossRef]

11. Jones, C.D.; Smith, L.F. Optimum arrangement of rectangular fins on horizontal surfaces for free convection heat transfer. J. Heat Transf. 1970, 92, 6-10. [CrossRef]

12. Turner, J. Buoyant convection from isolated sources. In Buoyancy Effects in Fluids; Cambridge University Press: Cambridge, UK, 1973; pp. 165-206.

13. Cebeci, T.; Bradshaw, P. Physical and Computational Aspects of Convective Heat Transfer; Springer Science \& Business Media: Berlin/Heidelberg, Germany, 2012.

14. Bar-Cohen, A. Fin thickness for an optimized natural convection array of rectangular fins. ASME J. Heat Transf. 1979, 101, 564-566. [CrossRef]

15. Bar-Cohen, A.; Rohsenow, W. Thermally optimum spacing of vertical, natural convection cooled, parallel plates. J. Heat Transf. 1984, 106, 116-123. [CrossRef]

16. Effendi, N.S.; Kim, K.J. Orientation effects on natural convective performance of hybrid fin heat sinks. Appl. Therm. Eng. 2017, 123, 527-536. [CrossRef]

17. Ong, K.; Tan, C.; Lai, K.; Tan, K. Heat spreading and heat transfer coefficient with fin heat sink. Appl. Therm. Eng. 2017, 112, 1638-1647. [CrossRef]

18. Baskaya, S.; Sivrioglu, M.; Ozek, M. Parametric study of natural convection heat transfer from horizontal rectangular fin arrays. Int. J. Therm. Sci. 2000, 39, 797-805. [CrossRef]

19. Harahap, F.; Lesmana, H.; Dirgayasa, I.A.S. Measurements of heat dissipation from miniaturized vertical rectangular fin arrays under dominant natural convection conditions. Heat Mass Transf. 2006, 42, 1025-1036. [CrossRef]

20. Bayat, M.; Faridzadeh, M.R.; Toghraie, D. Investigation of finned heat sink performance with nano enhanced phase change material (NePCM). Therm. Sci. Eng. Prog. 2018, 5, 50-59. [CrossRef]

21. Mandal, S.; Deb, A.; Sen, D. Mixed convective heat transfer with surface radiation in a rectangular channel with heat sources in presence of heat spreader. Therm. Sci. Eng. Prog. 2019, 14, 100423. [CrossRef]

22. Karvinen, R.; Karvinen, T. Optimum geometry of plate fins. J. Heat Transf. 2012, 134, 081801. [CrossRef]

23. Adhikari, R.; Wood, D.; Pahlevani, M. Optimizing rectangular fins for natural convection cooling using CFD. Therm. Sci. Eng. Prog. 2020, 17, 100484. [CrossRef]

24. Huang, G.J.; Wong, S.C.; Lin, C.P. Enhancement of natural convection heat transfer from horizontal rectangular fin arrays with perforations in fin base. Int. J. Therm. Sci. 2014, 84, 164-174. [CrossRef]

25. Micheli, L.; Fernández, E.F.; Almonacid, F.; Mallick, T.K.; Smestad, G.P. Performance, limits and economic perspectives for passive cooling of High Concentrator Photovoltaics. Sol. Energy Mater. Sol. Cells 2016, 153, 164-178. [CrossRef]

26. ANSYS. ANSYS Academic Research Icepak, Release 18; ANSYS: Canonsburg, PA, USA, 2018. 
27. Tari, I.; Mehrtash, M. Natural convection heat transfer from inclined plate-fin heat sinks. Int. J. Heat Mass Transf. 2013, 56, 574-593. [CrossRef]

28. Dogan, M.; Sivrioglu, M.; Y1lmaz, O. Numerical analysis of natural convection and radiation heat transfer from various shaped thin fin-arrays placed on a horizontal plate-a conjugate analysis. Energy Convers. Manag. 2014, 77, 78-88. [CrossRef]

(C) 2020 by the authors. Licensee MDPI, Basel, Switzerland. This article is an open access article distributed under the terms and conditions of the Creative Commons Attribution (CC BY) license (http:/ / creativecommons.org/licenses/by/4.0/). 